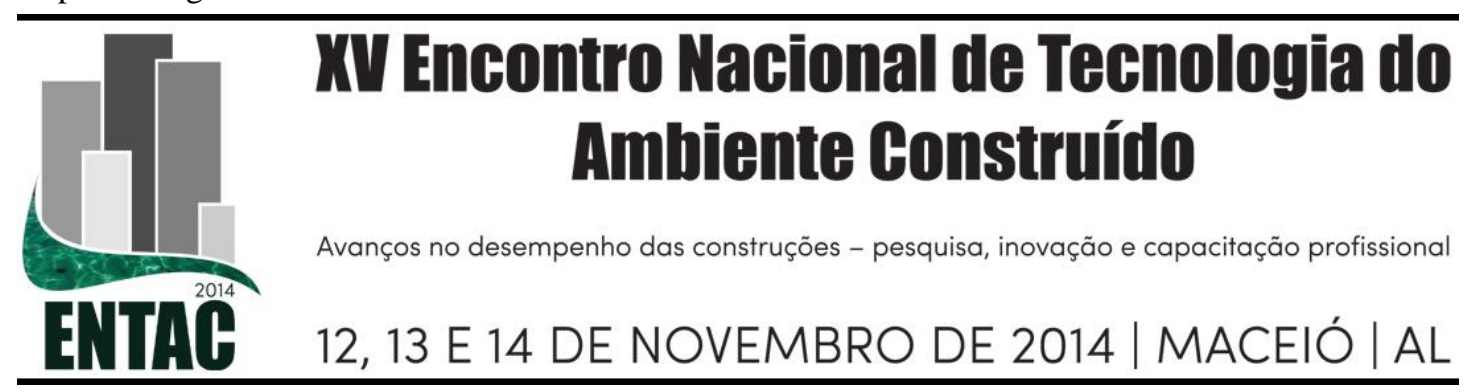

\title{
MEDIDAS DE IMPEDÂNCIA ELÉTRICA DE ARGAMASSAS CONTAMINADAS COM CHUMBO
}

\section{VENÂNCIO, Caroline (1); ROCHA, Janaíde C. (2); CHERIAF, Malik (3)}

(1) Universidade Federal de Santa Catarina, e-mail:caroline_venancio@yahoo.com.br (2) Universidade Federal de Santa Catarina, e-mail: janaide.rocha@ufsc.br, (3) Universidade Federal de Santa Catarina, email: malik.cheriaf@gmail.com

\section{RESUMO}

A espectroscopia de impedância eletroquímica (EIE) é utilizada amplamente no estudo dos materiais e neste caso, os materiais cimentícios também estão inseridos. A técnica permite a avaliação da estrutura, microestrutura e das propriedades físico-químicas durante e após a hidratação do cimento Portland. Neste estudo foram avaliadas a condutividade elétrica efetiva de argamassas contaminadas com nitrato de chumbo $\left(\mathrm{Pb}\left(\mathrm{NO}_{3}\right)_{2}\right)$ e a difusividade dos íons de chumbo ao longo de 64 dias, durante o ensaio de lixiviação, conhecido como Tank Test. Para a realização do ensaio de impedância elétrica, uma corrente alternada (AC) foi imposta, na faixa de frequência de $200 \mathrm{kHz}$ até $2 \mathrm{MHz}$. A contaminação com nitrato de chumbo foi realizada em quatro teores: 20, 40, 80 e 160 ppm do metal em relação à massa de cimento. Após o ensaio de lixiviação as argamassas com maiores concentração de chumbo, apresentaram os maiores valores de difusividade devido à maior liberação de hidróxido de cálcio. Aos 28 dias de cura das argamassas, todas as amostras contaminadas apresentaram valores de condutividades elétricas menores do que a argamassa sem contaminação. Em relação às condutividades efetivas, a contaminação com chumbo altera o comportamento elétrico das argamassas ao longo do período de hidratação, revelando uma tendência linear. Portanto, os materiais cimentícios produzidos com resíduos contaminados com chumbo, por exemplo, podem ser avaliados em relação a uma possível contaminação ambiental, por meio do Ensaio de Tanque, cuja duração é de 64 dias. No entanto, os ensaios elétricos podem vir a ser utilizados futuramente a fim de fornecer um rastreamento mais rápido desta contaminação e sem deixar de ser menos eficaz.

Palavras-chave: Argamassas, Impedância Elétrica, Chumbo.

\begin{abstract}
The spectroscopy of electrochemical impedance (SEI) is used in the study of building materials and in this case, the cementitious materials are also studied. Through of this technique, the structure, microstructure and the proprieties chemical and physics of building materials can be evaluated, during and after of the Portland cement hydration process. In this work, the effective electrical conductivity of the mortars contaminated with nitrate of lead $\left(\mathrm{Pb}\left(\mathrm{NO}_{3}\right)_{2}\right)$ and the diffusivity of lead ions was evaluated during the leaching test, specifically the Tank Test. On electrical test an alternating current (AC)
\end{abstract}


was imposed applying a frequency range of $200 \mathrm{kHz}$ until to $2 \mathrm{MHz}$. The contamination of the mortars with nitrate of lead was realized: 20, 40, 80 and 160 ppm of the heavy metal by weight of cement. After of the leaching test, the mortars with higher lead contamination showed the higher values of diffusivity due the higher leaching of hydroxide of calcium. At 28 days of curing of the mortars, all the samples contaminated showed conductivity higher than the mortar reference without contamination. During the cement hydration process, the presence of lead changed the electrical performance of the mortars. About the electrical conductivity effective, all the mortars contaminated showed a linear tendency along of the hydration process. In studies of case, cementitious materials with wastes incorporated, contaminated with lead, for example, they can be evaluated through the leaching test as Tank test, which duration is 64 days. However, in the other hand, the electrical tests can be used in the future for a fast evaluation of this contamination and it is not less effective.

Keywords: Mortars, Electrical Impedance, Lead.

\section{INTRODUÇÃO}

As medidas elétricas possibilitam uma vasta análise da microestrutura das matrizes cimentícias, contribuindo no estudo de determinadas propriedades como a condutividade elétrica, associada à rede de poros, a condutividade hidráulica, tortuosidade, teor de umidade, entre outros parâmetros como a evolução do processo de hidratação. Além de auxiliar na avaliação do comportamento mecânico das matrizes cimentícias, como também a durabilidade, a técnica de impedância elétrica pode ser complementar à análise do potencial de lixiviação de contaminantes, ou seja, do risco de liberação de poluentes. O mecanismo de transporte dos fluidos e a mobilidade dos íons dos metais pesados, dentro das matrizes cimentícias, influenciarão nas medidas de condutividade e de resistividade elétricas. O tamanho dos poros, a conectividade entre eles, a tortuosidade e a difusão, são propriedades de um meio poroso que definirá as possibilidades de lixiviação dos contaminantes. Uma vez compreendidos estes fenômenos, a partir das medidas elétricas, os ensaios de lixiviação poderão ser mais eficazes e rápidos na avaliação dos materiais e dos componentes produzidos com a valorização dos subprodutos industriais. O método de impedância elétrica pode avaliar a interação da matriz cimentícia com os contaminantes durante o processo de hidratação, é um método não destrutivo e possível de se realizar in loco.

No presente artigo, a impedância elétrica foi utilizada como uma técnica de identificação da presença do chumbo nas argamassas, previamente contaminadas com nitrato de chumbo $\left(\mathrm{Pb}\left(\mathrm{NO}_{3}\right)_{2}\right)$ e a lixiviação do metal pesado foi acompanhada por meio dos ensaios de lixiviação "Tank Test" NEN-7375 (2004), durante 64 dias de ensaio em condições imersas e com renovação do líquido lixiviante em oito períodos. As medidas de impedância foram realizadas nas amostras anteriormente ao ensaio de lixiviação e durante as extrações e renovação do líquido lixiviante, durante o ensaio de Tanque. Nas medições anteriores ao ensaio de tanque, obtiveram-se os espectros de impedância que permitem a determinação da condutividade elétrica efetiva das argamassas e da permissividade elétrica. As medidas elétricas realizadas nas argamassas contaminadas durante o ensaio de tanque permitiram avaliar o comportamento da impedância elétrica ao longo do processo de difusão. 


\section{REVISÃO BIBLIOGRÁFICA}

A espectroscopia de impedância eletroquímica (EIE) é utilizada amplamente no estudo dos materiais e neste caso, também se incluem os materiais cimentícios. Juntamente a outras técnicas analíticas (porosimetria, DRX, MEV, etc.) a medida da impedância elétrica pode torna-se uma ferramenta bastante poderosa e eficiente para caracterizar os materiais cimentícios (LOCHE et. al, 2005).

Cada componente do material cimentício (compostos hidratados, compostos anidros, fase sólida, fase gel, poros e eletrólito preenchendo os poros) participa como um elemento resistivo ou capacitivo, formando um circuito elétrico equivalente que representará todo o material. A pasta de cimento é eletricamente condutiva, em virtude da rede de poros interligados que estão preenchidos com água. E na água, por sua vez, estão dispersos os íons liberados pelo cimento após a sua dissolução e no início da sua hidratação. Logo, é vital a compreensão do desenvolvimento da estrutura da matriz para se conhecer o comportamento de várias outras propriedades da argamassa e dos concretos, como: resistência mecânica, estabilidade volumétrica, características higroscópicas e durabilidade (SCHWARZ et. al, 2007).

A EIE permite encontrar as propriedades dielétricas dos materiais, que por sua vez, refletem claramente o desenvolvimento da estrutura porosa e o grau de preenchimento destes poros pelo eletrólito (FAYALA et. al, 2013). Portanto, algumas propriedades de fluxo e de transporte de massa também podem ser determinadas por meio das medidas de impedância elétrica, como a difusividade e a condutividade hidráulica.

\section{MATERIAIS E MÉTODOS}

\subsection{Materiais utilizados e produção das argamassas}

As argamassas foram produzidas com o uso do cimento Portland CPV - ARI, na composição unitária de (1:2), cimento e areia e relação água e cimento $(\mathrm{a} / \mathrm{c})$ igual a 0,50 . As argamassas foram contaminadas com nitrato de chumbo $\left(\mathrm{Pb}\left(\mathrm{NO}_{3}\right)_{2}\right)$, padrão analítico, em concentrações de : 20, 40, 80 e 160 ppm (em relação a massa do cimento). Para o ensaio de EIE foram utilizadas amostras cilíndricas de dimensões: diâmetro de 5 $\mathrm{cm}$ e altura de $10 \mathrm{~cm}$, que foram seccionadas antes do ensaio, na altura de $3 \mathrm{~cm}$. Para $\mathrm{o}$ ensaio de lixiviação as amostras apresentam dimensões: diâmetro de $5 \mathrm{~cm}$ altura de 10 $\mathrm{cm}$. Após a moldagem e durante todo o período de cura, as amostras foram protegidas com filme, evitando o processo de carbonatação e permaneceram em ambiente com temperatura e umidade relativa do ar, controladas $\left(\mathrm{T}=23 \pm 2{ }^{\circ} \mathrm{C}\right.$, e UR de $\left.50 \%\right)$. Para avaliar o efeito do chumbo na hidratação das matrizes, as amostras foram ensaiadas nas idades de 3, 7, 14 e 28 dias, em relação às medidas de impedância. Para a avaliação do potencial de lixiviação foram testadas as amostras com 28 dias de cura.

\subsection{Medidas Elétricas}

Para avaliar o desenvolvimento do processo de hidratação das amostras e a possível influência do chumbo no processo de hidratação das argamassas foi realizado o ensaio de medida da impedância elétrica, ao longo de 3, 7, 14 e 28 dias de cura. As medidas foram conduzidas na argamassa de referência, denominada de REF e nas amostras contaminadas com chumbo, denominadas $\mathrm{Pb} 20, \mathrm{~Pb} 40, \mathrm{~Pb} 80$ e $\mathrm{Pb} 160$.

A impedância elétrica é expressa em ohms, e designada pelo símbolo Z. A impedância indica a oposição total que um circuito oferece ao fluxo de uma corrente 
elétrica variável no tempo, ou seja, num circuito de corrente alternada (AC). Matematicamente, a determinação da impedância elétrica é apresentada na Equação 1.

$$
Z=\frac{V}{I}
$$

Aplicando-se uma tensão alternada $\mathrm{V}(\mathrm{t})$ de frequência angular $\omega$, tem-se como resposta uma corrente alternada $I(t)$ e o ângulo $\theta(t)$ é a defasagem entre a tensão e a corrente. $O$ gráfico resultante do espectro da impedância elétrica, o gráfico Nyquist, é resultante de um plano complexo (real e imaginário). $O$ espectro descreve um arco simples. Z'(resistência elétrica), no eixo das abscissas é a parte real (Equação 2), e Z' '(reatância elétrica), no eixo das ordenadas, é a parte imaginária da impedância elétrica (Equação $3)$.

Figura 1 - Gráfico típico Nyquist

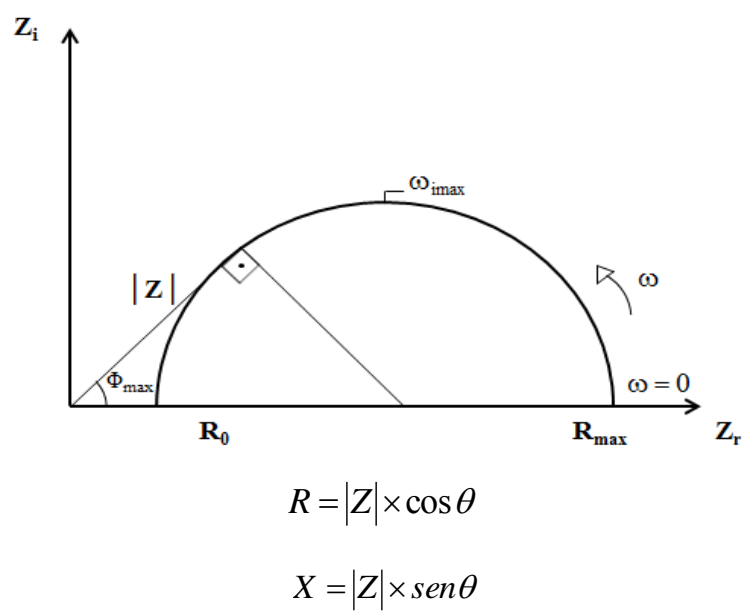

Para a realização do ensaio, uma corrente alternada foi imposta, na faixa de frequência de $200 \mathrm{kHz}$ até $2 \mathrm{MHz}$. A corrente elétrica e a tensão foram medidas no osciloscópio digital, modelo Tektronik, e o gerador de corrente elétrica alternada é da marca Minipa, modelo MFG - 4201A. Outras propriedades elétricas das argamassas também foram medidas: a capacitância da amostra (C) e a permissividade elétrica ( $(\varepsilon)$. As equações para o cálculo da capacitância e da permissividade estão apresentadas nas Equações 4 e 5.

$$
\begin{gathered}
C=\frac{1}{2 \cdot \pi \cdot f \cdot Z} \\
\varepsilon=\frac{C d}{A}
\end{gathered}
$$

Onde, $\mathrm{C}=$ capacitância $[\mathrm{F}]$;

$\mathrm{f}=$ frequência $[\mathrm{Hz}]$

$\mathrm{Z}=$ impedância elétrica $[\Omega]$;

$\varepsilon=$ permissividade elétrica $[\mathrm{F} / \mathrm{m}]$

$\mathrm{d}=$ distância entre os eletrodos [m ];

$\mathrm{A}=$ área dos eletrodos em contato com a amostra $\left[\mathrm{m}^{2}\right]$.

Outro parâmetro também avaliado durante o ensaio elétrico foi a constante dielétrica das argamassas, determinada por meio da relação existente entre a permissividade elétrica do material e a permissividade elétrica no vácuo $\left(\varepsilon / \varepsilon_{0}\right.$, sendo $\left.\varepsilon_{0}=8,854187.10-12 \mathrm{~F} / \mathrm{m}\right)$. No típico gráfico Nyquist, quando o arco intercepta o eixo das abcissas (Figura 1), a parcela imaginária da impedância é mínima e a resistência elétrica encontrada é máxima 
$\left(\mathrm{R}_{\text {máx }}\right)$. Esta resistência é conhecida como a resistência total da amostra. E a partir desta resistência, determina-se a condutividade elétrica efetiva $\left(\sigma_{\text {eff }}\right)$ da amostra por meio da Equação 6.

$$
\sigma_{\text {eff }}=\frac{l}{R_{\max } A}
$$

Onde, $l=$ comprimento da amostra $(\mathrm{m})$;

$R=$ resistência elétrica $(\Omega)$;

$A=$ área transversal do corpo de prova $\left(\mathrm{m}^{2}\right)$.

A condutividade efetiva das argamassas se mantem constante por uma longa faixa de variação da frequência, ou seja, no gráfico da condutividade versus a frequência, tem-se evidente um patamar que se estende por uma faixa de frequência bastante ampla, como de $1 \mathrm{~Hz}$ até $10 \mathrm{MHz}$ (SCHWARZ et al. 2007, NEITHALATH N., 2007).

\subsection{Ensaio de Lixiviação}

O teste de lixiviação aplicado às argamassas foi o ensaio de tanque. Onde as amostras permanecem submersas em água destilada e deionizada, dentro de tanques, durante períodos preconizados na norma NEN-7375 (2004). Ao final de cada intervalo de tempo $(0,25 ; 1,2,25 ; 4 ; 9 ; 16 ; 36$ e 64 dias $)$, o líquido lixiviante foi coletado e filtrado para análise dos elementos químicos que lixiviaram da matriz cimentícia, sendo os tanques novamente preenchidos com nova solução lixiviante. A renovação da água nos tanques confere um gradiente de concentração entre os dois meios (argamassa-água), mantendo a difusão dos elementos químicos que pode ser determinada por meio da Equação 7. A identificação da concentração do contaminante na solução extraída dos tanques foi realizada por meio da técnica de espectroscopia por difração de raios-X (EDX).

$$
D e=\left(\frac{\varepsilon_{64}}{2653 \times \rho \times U_{\text {máx }}}\right)^{2} \times f
$$

Onde, $\varepsilon_{64}=$ liberação do elemento químico após os 64 dias de ensaio, em mg/m²;

$\rho=$ densidade das argamassas em $\mathrm{kg} / \mathrm{m}^{3}$;

$U_{\text {máx }}=$ máxima concentração do elemento químico que pode ser lixiviada das argamassas, em $\mathrm{mg} / \mathrm{kg}$;

$f \quad=$ fator de conversão igual a $1 \mathrm{~s}^{-1}$.

A determinação da concentração máxima possível de ser liberada das argamassas $\left(U_{\text {máx }}\right)$ foi determinada por meio da análise química, realizada em amostras finamente divididas (moagem para dimensão inferior $150 \mu \mathrm{m}$ ), empregando-se a técnica de EDX.

\subsection{Ensaio Elétrico e Ensaio de Lixiviação}

Durante o ensaio de lixiviação no tanque, a cada renovação do líquido dos tanques, as amostras foram retiradas do tanque para a leitura da impedância elétrica, numa frequência fixa, igual a $200 \mathrm{kHz}$. Como as amostras estavam com uma maior quantidade de água absorvida, devido à imersão nos tanques, uma baixa frequência foi suficiente para a realização das leituras da impedância elétrica. 


\section{RESULTADOS E DISCUSSÃO}

\subsection{Medidas elétricas durante a hidratação}

A Figura 2 representa a condutividade elétrica efetiva determinada durante as diferentes idades de cura: 3, 7, 14 e 28 dias. Verificou-se que a condutividade elétrica efetiva diminuiu com o aumento da idade de cura e em maior proporção para as amostras contaminadas ( $\mathrm{Pb} 40, \mathrm{~Pb} 80$ e $\mathrm{Pb}$ 160). Isto significa que a contaminação com chumbo interfere de forma direta e proporcional à condutividade elétrica efetiva.

Figura 2 - Condutividade efetiva das argamassas contaminadas com $\mathrm{Pb}^{2+}$.

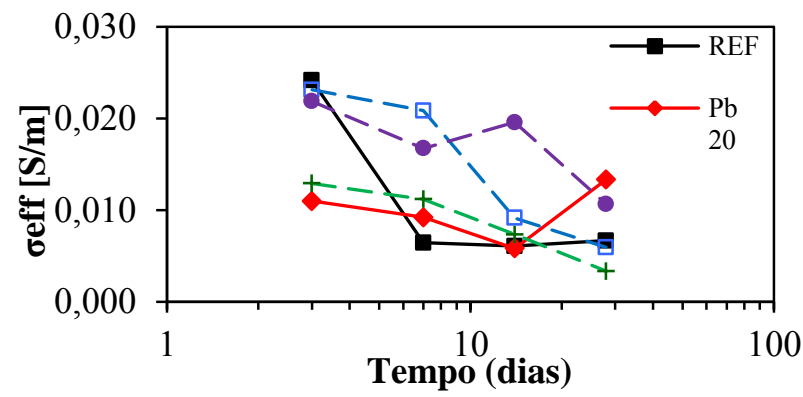

Aos 28 dias de cura (Figura 3) todas as argamassas contaminadas apresentaram uma condutividade elétrica menor do que a argamassa de referência. As argamassas dopadas com chumbo apresentam poros de menor diâmetro, ou seja, ocorre um refinamento dos poros, fato que origina uma maior resistência elétrica da amostra e uma menor condutividade elétrica (GINEYS et al., 2010; LASHERAS-ZUBIATE et al., 2012).

Figura 3 - Condutividade efetiva das argamassas contaminadas com $\mathrm{Pb}^{2+}$.

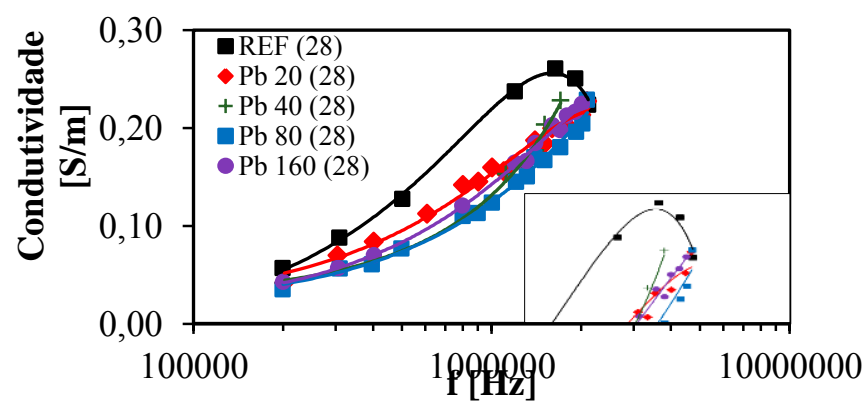

Na Figura 4 estão apresentados os valores da constante dielétrica das argamassas com 28 dias de cura. Durante toda a faixa de frequência analisada, as argamassas contaminadas apresentaram constante dielétrica maior do que a argamassa sem contaminação. O comportamento da constante dielétrica das matrizes cimentícias é contrário ao comportamento da condutividade elétrica (NEITHALATH N., 2007), como pode ser comprovado com as Figuras 3 e 4. Com a presença do chumbo, as argamassas apresentaram uma maior capacidade de rearranjar as suas moléculas, frente à aplicação de um campo elétrico. Possivelmente devido aos íons de chumbo que tem um papel principal neste rearranjo e transmissão da corrente elétrica.

Figura 2 - Constante dielétrica das argamassas com 28 dias de cura. 


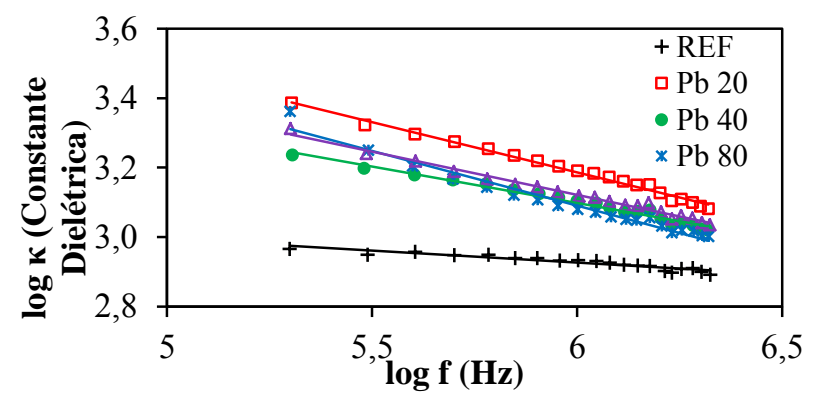

Após o ensaio de lixiviação, a constante dielétrica das argamassas também foi avaliada e será mais bem discutida para a análise da lixiviação do chumbo e de outros elementos químicos.

\subsection{Ensaio de Lixiviação}

Avaliando a lixiviação do cálcio das argamassas durante o ensaio de tanque, todas as argamassas contaminadas liberaram uma quantidade maior de cálcio do que a argamassa de referência. De acordo com Labhasetwar N. e Shrivastava o. P. (1989) ocorre uma troca iônica entre o $\mathrm{Ca}^{2+}$ do silicato de cálcio hidratado $(\mathrm{C}-\mathrm{S}-\mathrm{H})$ e o $\mathrm{Pb}^{2+}$. Em decorrência dessa troca iônica, aumenta a quantidade dos íons $\mathrm{Ca}^{2+}$ na solução. No caso do ensaio de lixiviação, esse aumento de cálcio é verificado na água do tanque que é analisada por EDX e está apresentada na Figura 5.

\section{Figura 3 - Lixiviação do $\mathrm{Ca}^{2+}$ durante o Ensaio de Tanque.}

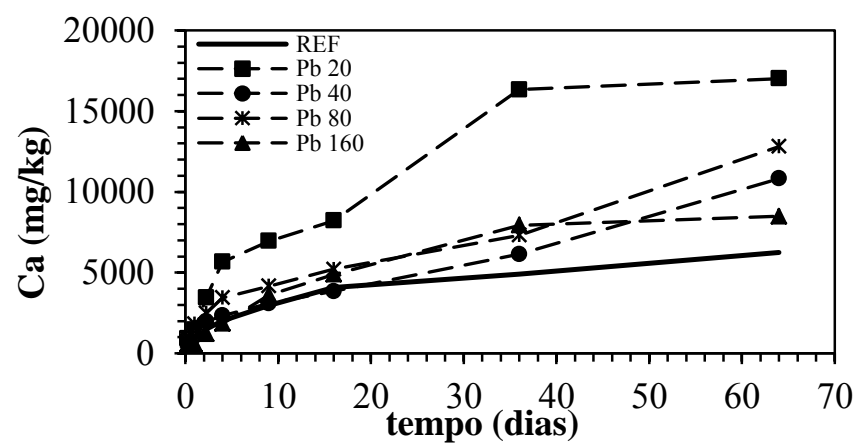

Com a adição do chumbo nos materiais cimentícios, a quantidade de portlandita $\left(\mathrm{Ca}(\mathrm{OH})_{2}\right)$ liberada durante ensaios de lixiviação é maior (LEE et al., 2005). Este fato decorre da maior formação de carbonatos e hidróxidos, por meio da precipitação dos íons metálicos, aumentando a concentração de cálcio livre na matriz cimentícia (MALVIYA R. e CHAUDHARY R., 2006). Todas as argamassas contaminadas com chumbo liberaram uma quantidade maior de cálcio do que a amostra de referência, possivelmente devido à troca iônica existente $\left(\mathrm{Pb}^{2+} \leftrightarrow \mathrm{Ca}^{2+}\right)$. Como resultado desta interação, no trabalho de Lee et al. (2005) foram identificados por DRX dois compostos, denominados de: hidróxido de sulfato-carbonato de chumbo $\left(\mathrm{Pb}_{4} \mathrm{SO}_{4}\left(\mathrm{CO}_{3}\right)_{2}(\mathrm{OH})_{2}\right)$ e hidróxido de carbonato de chumbo hidratado $\left(3 \mathrm{PbCO}_{3} \cdot 2 \mathrm{~Pb}(\mathrm{OH})_{2} \cdot \mathrm{H}_{2} \mathrm{O}\right)$.

No entanto, esperava-se que a argamassa com a maior concentração de chumbo, liberasse a maior quantidade de cálcio (devido à maior quantidade de troca iônica). Este fato não foi verificado possivelmente devido a outros fatores como a porosidade e a tortuosidade dos poros. Fatores estes que também podem ter influenciado na liberação do chumbo das argamassas (Figura 6). 


\section{Figura 4 - Liberação do $\mathrm{Pb}^{2+}$ durante 64 dias no Ensaio de Tanque.}

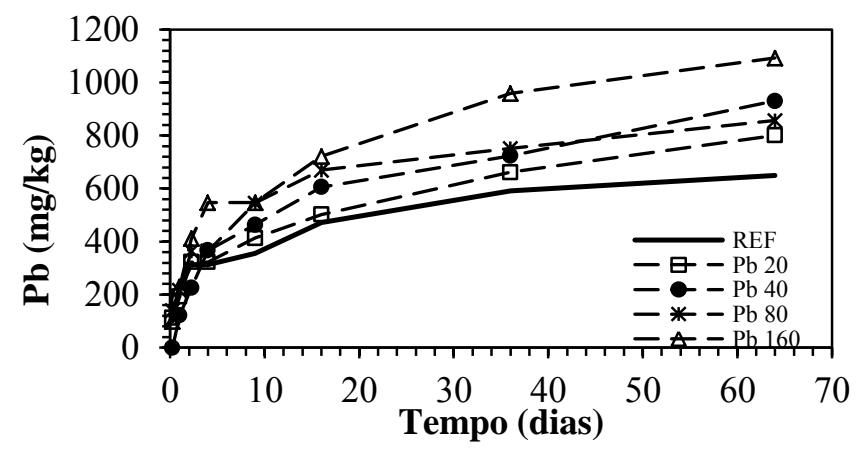

Na liberação acumulada do chumbo durante o ensaio de tanque, nos períodos de 9 até 36 dias, a quantidade de chumbo liberada é tanto maior quanto a contaminação das argamassas com chumbo. No entanto, esta proporção não foi verificada nos demais períodos do ensaio. Ainda que a liberação de chumbo tenha sido maior nas amostras contaminadas do que na argamassa sem contaminação, a análise da difusividade (Figura 7), durante todo o ensaio de tanque, demonstrou que a velocidade com que o metal pesado é lixiviado, foi maior para a amostra de referência do que nas argamassas contaminadas. Isto significa que, embora as argamassas contaminadas estejam liberando uma quantidade maior de chumbo, a velocidade desta liberação é reduzida, ou seja, o potencial de liberação do chumbo é limitado, comparado com o potencial de liberação do chumbo de uma argamassa não contaminada.

Figura 5 - Difusividade do chumbo, presente nas argamassas, durante o Ensaio de Tanque.

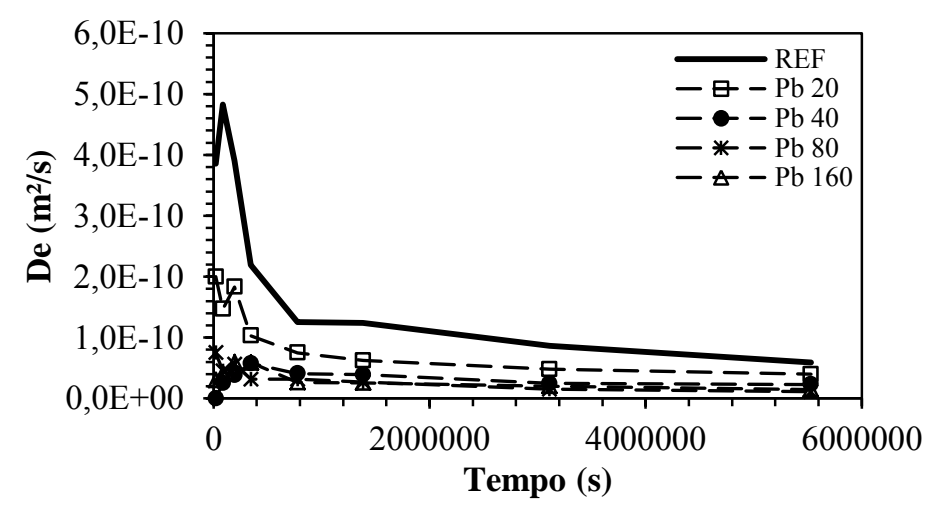

\subsection{Ensaio Elétrico e Ensaio de lixiviação}

A relação existente entre a difusividade durante todo o ensaio de lixiviação e a medida da impedância elétrica das argamassas contaminadas está apresentada na Figura 8.

A argamassa sem contaminação apresenta uma grande variação da difusividade durante o ensaio de tanque em relação à impedância elétrica e as duas grandezas são inversamente proporcionais. De acordo com os resultados obtidos para a REF, quanto maior a difusividade, menor a impedância elétrica. No entanto, de acordo com as Figuras 6 e 7, esta argamassa liberou baixa concentração de chumbo e de cálcio. Ou seja, esta grande variação da difusividade em relação à impedância elétrica é devido a permanência dos elementos químicos que não foram lixiviados e que se organizam e reorganizam com a aplicação da corrente elétrica. 
Figure 6 - Relação entre a difusividade e a impedância elétrica durante o Ensaio de Tanque.

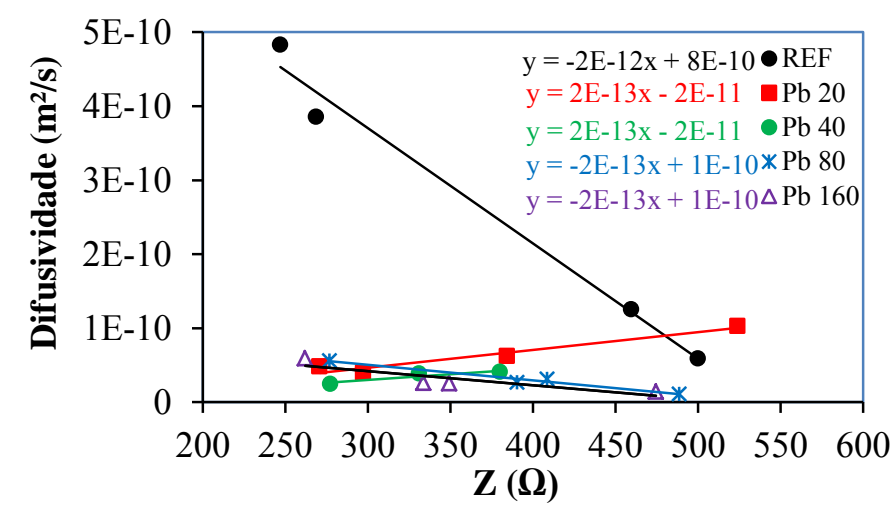

O comportamento da constante dielétrica de todas as amostras, após o ensaio de tanque (Figura 9), foi diferente da análise realizada antes do ensaio de lixiviação (Figura 4). A constante dielétrica está associada às mudanças microestruturais (NEITHALATH N., 2007). A presença de novas fases sólidas ou a liberação destas, como ocorre no ensaio de lixiviação ocasiona a mudança do comportamento da constante dielétrica.

A dependência linear desta constante em relação à frequência aplicada, aos 28 dias de cura (antes da lixiviação dos elementos químicos) tornou-se uma correlação potencial após o ensaio de lixiviação. Outro fato observado refere-se que maiores valores de difusão ao longo do ensaio de tanque (Figura 7) apresentaram valores maiores da constante dielétrica.

Figura 7 - Constante dielétrica das argamassas após o ensaio de tanque.

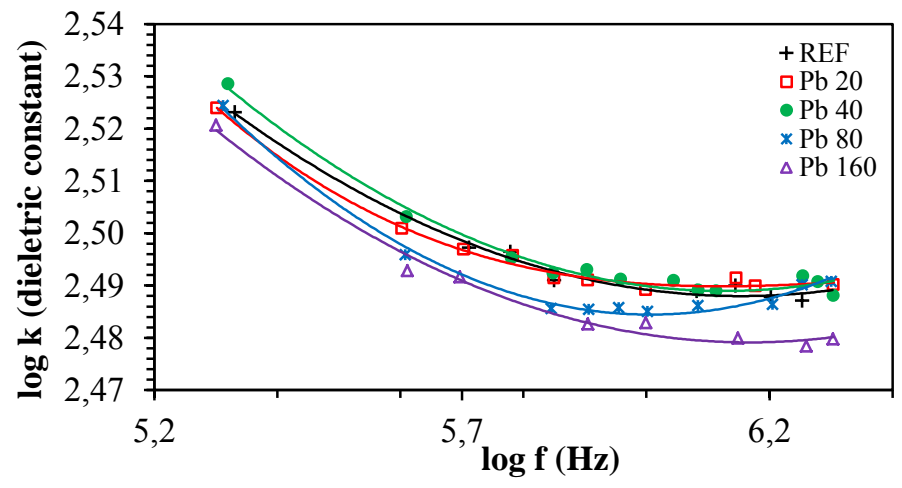

Se compararmos a liberação de cálcio das argamassas (Figura 5) e a constante dielétrica aos 28 dias de cura (Figura 4), antes das amostras serem submetidas ao ensaio de lixiviação, a amostra $\mathrm{Pb} 20$ apresentou a maior constante dielétrica e foi a amostra que mais liberou cálcio durante o ensaio de tanque. Ao contrário da argamassa REF, esta amostra liberou a menor quantidade de cálcio e foi a amostra que apresentou os menores valores de constante dielétrica. Assim, num estudo futuro, a liberação de cálcio poderá ser prevista pelos valores obtidos da constante dielétrica das argamassas.

\section{CONSIDERAÇÕES FINAIS}

Visto que a lixiviação do chumbo das argamassas com maiores teores de contaminação não liberaram mais chumbo do que as argamassas menos contaminadas, foi possível 
constatar que a lixiviação do chumbo depende de vários outros fatores como a porosidade e conectividade dos poros da argamassa.

As medidas elétricas realizadas durante o ensaio de lixiviação mostraram que a liberação do cálcio, presente no produto de hidratação conhecido como a portlandita, é preponderante nas medidas elétricas. $\mathrm{O}$ próprio chumbo influenciou na presença ou ausência do cálcio, devido às trocas iônicas entre $\mathrm{Pb}^{2+} \leftrightarrow \mathrm{Ca}^{2+}$. Esta troca iônica refletiu em maiores lixiviações do cálcio e menores valores de permissividade elétrica após o ensaio de tanque. Assim, num estudo futuro, a liberação de cálcio poderá ser prevista pelos valores obtidos da constante dielétrica das argamassas.

A espectroscopia de impedância eletroquímica pode ser utilizada para detectar a presença de chumbo em argamassas, uma vez que, propriedades como a condutividade elétrica e a constante dielétrica das amostras contaminadas se distinguiram da amostra de controle. No entanto, o nível de contaminação ainda não pôde ser bem distinguido por meio das medidas elétricas.

\section{AGRADECIMENTOS}

Os autores agradecem ao $\mathrm{CNPq}$ pelo suporte financeiro.

\section{REFERÊNCIAS}

EA NEN 7375 - Leaching characteristics of moulded or monolithic building and waste materials. Determination of leaching of inorganic components with the diffusion test. Netherlands Normalisation Institute Standard (2004).

I. Fayala, L. Dhouibi, X.R. Nóvoa, M. Ben Ouezdou. Effect of inhibitors on the corrosion of galvanized steel and on mortar properties. Cement \& Concrete Composites 35 (2013) 181-189.

N. Gineys, G. Aouad, D. Damidot. Managing trace elements in Portland cement - Part I: Interactions between cement paste and heavy metals added during mixing as soluble salts. Cement \& Concrete Composites 32 (2010) 563-570.

N. Labhasetwar, O. P. Shrivastava. $\mathrm{Ca}^{2+} \leftrightarrow \mathrm{Pb}^{2+}$ exchange reaction of calcium silicate hydrate: $\mathrm{Ca}_{5} \mathrm{Si}_{6} \mathrm{O}_{18} \mathrm{H}_{2} \cdot 4 \mathrm{H}_{2} \mathrm{O}$. Journal of Materials Science 24 (1989) 4359 - 4362.

M. Lasheras-Zubiate, I. Navarro-Blasco, J. M. Fernández, J. I. Álvarez. Encapsulation, solid-phases identification and leaching of toxic metals in cement systems modified by natural biodegradable polymers. Journal of Hazardous Materials 233 - 234 (2012) 7 - 17.

LEE, D., WAITE, D. T., SWARBRICK, G., LEE, S. Comparison of solidification/stabilization effects of calcite between Australian and South Korean cements. Cem. Concr. Res. 35 (2005) $2143-2157$.

J.M. Loche, A. Ammar, P. Dumargu. Influence of the migration of chloride ions on the electrochemical impedance spectroscopy of mortar paste. Cem. Concr. Res. 35 (2005) 17971803.

R. Malviya, R. Chaudhary. Factors affecting hazardous waste solidification/stabilization: A review. Journal of Hazardous Materials B137 (2006) 267-276.

N. Neithalath. Extracting the performance predictors of Enhanced Porosity Concretes from electrical conductivity spectra. Cem. Concr. Res. 37 (2007) 796-804.

N. Schwarz, M. DuBois, N. Neithalath. Electrical conductivity based characterization of plain and coarse glass powder modified cement pastes. Cement \& Concrete Composites 29 (2007) $656-666$. 